\title{
CONTRIBUIÇÃO PARA O CONHECIMENTO DA ALIMENTAÇÃO DE JAMANTAS JOVENS (MANTA EHRENBERGII Mueller \& Henle)
}

\section{Victor Sadowsky}

As jamantas da espécie Manta ehrenbergii Mueller \& Henle, são relativamente mais raras na costa brasileira (Ribeiro, 1923; Carvalho, 1943; von Ihering, 1940; Fowler, 1942) do que os representantes da espécie Manta birostris (Walbaum).

$\mathrm{Na}$ região sul da costa paulista, cêrca de $25^{\circ}$ de latitude sul, êsses peixes aparecem com regularidade durante os meses quentes. Os exemplares adultos, de dimensões próximas aos máximos da espécie, ou seja, cêrca de 4 ou $5 \mathrm{~m}$ de medida transversal, podem ser observados perto da superfície, nadando em pequenos cardumes de três a cinco espécimes ou mesmo isoladamente.

Peixes de tamanho menor são capturados com relativa freqüência em rêdes de diversos tipos, sendo que a sua carne costuma ser desprezada pela população local.

Durante a realização dos trabalhos de pesca experimental e estudos relacionados com os seláquios, na região da Barra de Cananéia, no verão de 1959, foram capturadas várias jamantas jovens de 100 a $160 \mathrm{~cm}$ de comprimento transversal (medida entre uma ponta e outra das asas).

O exame do conteúdo estomacal, em todos os oito casos, revelou a presença de várias quantidades de zoo e fitoplancton. Em um caso, encontramos também duas lulas (Lologinídeos) e, em outro, restos de 14 ou 15 larvas de peixes de 2 a $4 \mathrm{~cm}$ de comprimento, em avançado estado de decomposição.

No mês de fevereiro, foi capturado um espécime maior, de $251 \mathrm{~cm}$ de largura, cujo estômago estava repleto de uma espécie de massa compacta, de côr cinzento-amarelada. Êsse conteúdo era 
composto de plancton, apresentando dominância de copépodos e elementos insignificantes de diatomáceas, porém sem nenhum componente de macroorganismo. O exame mais detalhado, efetuado pela Dra. T. K. S. Björnberg, planctonologista do Instituto Oceanográfico, apresentou o seguinte resultado: dominante - copépodos do gênero Acartia; subdominante - copépodos dos gêneros Corycaeus e Calanopia, sendo encontradas ainda larvas de vários crustáceos, não identificados e diatomáceas, com predominância do gênero Coscinodiscus.

\section{S U M M A R Y}

The present note is concerned with the food habits of young Manta envenbergii (manta) captured at the southern coast of São Paulo State. The author examined the stomach contents of the specimens and found besides zoo and phytoplankton, some squids, copepods, crustacean and fish larvae. Among the diatoms present, Coscinodiscus was the dominant genus.

B I B L I O G R A F I A

Carvalho, J. de P.

1943. Nota preliminar sôbre a fauna ictiológica do litoral sul do Estado de São Paulo. Bol. Ind. Animal, n. ${ }^{\circ}$ 150, p. 39.

Fowler, H. W.

1942. A list of the fishes of Brazil. Arq. Zool. São Paulo, vol. III, p. 132 .

IHERING, R. von

1940. Dicionário dos animais do Brasil. São Paulo, Secretaria da Agricultura, Diretoria de Publicidade Agrícola.

RibeIro, A. de

1923. Fauna Brasiliense, vol. II, $1^{\text {3 }}$ parte, fasc. I, p. 50. 